\title{
Developing a Risk-Based Approach for Optimizing Human Reliability Assessment in an Offshore Operation
}

\author{
Ahmad BahooToroody', Mohammad Mahdi Abaiee ${ }^{2}$, Reza Gholamnia ${ }^{3 *}$, \\ Mohammad Bahoo Torody 4 , Nastaran Hekmat Nejad ${ }^{5}$ \\ ${ }^{1}$ Faculty of Engineering, Kar Higher Education Institute of Qazvin, Qazvin, Iran \\ ${ }^{2}$ Faculty of Marine Technology, Amirkabir University of Technology Tehran, Tehran, Iran \\ ${ }^{3}$ School of Health Safety and Environment, Shahid Beheshti University of Medical Science, Tehran, Iran \\ ${ }^{4}$ Faculty of Engineering, Azad University of Zanjan, Zanjan, Iran \\ ${ }^{5}$ Faculty of Engineering, Kar Higher Education Institute of Qazvin, Qazvin, Iran \\ Email: "gholamnia@sbmu.ac.ir
}

Received 25 January 2016; accepted 25 March 2016; published 28 March 2016

Copyright (C) 2016 by authors and Scientific Research Publishing Inc.

This work is licensed under the Creative Commons Attribution International License (CC BY).

http://creativecommons.org/licenses/by/4.0/

(c) (i) Open Access

\section{Abstract}

Human error plays a pivotal rule in all aspects of engineering activities such as operation, maintenance, design, inspection and installation. Industries are faced up to various significant human errors and consequently irrecoverable loss each year, but still there is a lack of heeds to qualify as well as quantify such errors. This paper tries to estimate the probability of failure in lifting of light structures in sea by considering human errors. To do this, a strong qualifying tool such as Functional Resonance Analysis Method (FRAM) is applied to develop high risk accident scenario by considering non-linear socio-technical interaction in system. Afterwards, human error probability is calculated for each activity using the Success Likelihood Index Method (SLIM) based on resonance that is carried out in FRAM network. Then Event Tree (ET) is conducted to assess consequences. The present study is aimed to interpret the importance of attentions to qualitative methods in implementing quantitative risk analyses to consider human error in calculation. The final outcome depicts that considering human error in the process of risk assessment will result in more accuracy and reliability in final Risk Probability Number (RPN). The developed methodology has been applied to a case study of an offshore installation.

\section{Keywords}

Risk-Based Assessment, Probability of Failure, Accident Scenario, FRAM, SLIM, ET

\footnotetext{
${ }^{*}$ Corresponding author.
}

How to cite this paper: BahooToroody, A., Abaiee, M.M., Gholamnia, R., Torody, M.B. and Nejad, N.H. (2016) Developing a Risk-Based Approach for Optimizing Human Reliability Assessment in an Offshore Operation. Open Journal of Safety Science and Technology, 6, 25-34. http://dx.doi.org/10.4236/ojsst.2016.61003 


\section{Introduction}

Risk assessment is a systematic process for analyzing and evaluating events that could affect the achievement of objectives, positively or negatively. Such events can be identified in the external environment and within an organization's internal environment. It is necessary to define both risk analyzing and risk evaluating to represent the risk assessment clearly. Risk analyzing is therefore defined as systematic use of available information to identify hazards and to estimate the risk to individuals, property, and the environment [1]. Besides, risk evaluating is means that process in which judgments are made on the tolerability of the risk on the basis of a risk analysis and taking into account factors such as socioeconomic and environmental aspects [1]. The risk evaluation will sometimes include a comparison of the results from the risk analysis with some risk acceptance criteria. Risk assessment is intended to provide management with a view of events that could impact the achievement of objectives.

The risk analysis may be qualitative or quantitative, depending on the objective of the analysis. Qualitative risk analysis is a risk analysis where probabilities and consequences are determined purely qualitatively. Qualitative assessments are the most basic form of risk assessment, categorizing potential risks based on either nominal or ordinal scales. Whereas quantitative risk analysis (QRA) is determined as risk analysis that provides numerical estimates for probabilities and/or consequences-sometimes along with associated uncertainties. A QRA is best suited for quantifying risk associated with low-probability and high-consequence events, and may range from specialized probabilistic assessment to large-scale analysis. The term semi-quantitative risk analysis is sometimes used to denote risk analyses that quantify probabilities and consequences approximately within ranges.

As part of these assessments, risk and reliability analysts are required to perform evaluations of human reliability in addition to the analyses of hardware systems which are the primary focus of a typical risk assessment. Increasing emphasis is being placed on a comprehensive assessment of the human role in system safety following the occurrence of major disasters in the petrochemical industry such as Piper Alpha and other industries like Chernobyl where human errors are seen as direct or indirect causes. A better estimate of human reliability would help to design more effective safety systems and evaluate more accurate risk assessments. Human reliability is the probability that a person correctly performs system-required activities in a required time period (if time is a limiting factor) [2]. Human reliability is related to the field of human factors engineering and involves the study of human Performance Shaping Factors (PSF) [3] The safety of offshore installations often requires claims on human action. Where safety of substantial human actions and administrative controls are required and their need is justified, the feasibility and reliability of the actions are demonstrated qualitatively using task analysis. This qualitative modelling is used to substantiate any human-based safety claims and the quantitative modelling of the probability of the associated human errors. It is necessary to carry out task decomposition and analysis of sufficient depth in order to understand what is being assessed, the demands and influencing factors on personnel and to assist with the identification of reasonably practicable design options or improvements to support human reliability. Task analysis provides the necessary support to the HRA process for this demonstration of adequacy. The first part of the paper will discuss the implications of qualitative analysis for quantitative risk assessment. A network of Functional Resonance Analysis Method (FRAM) [4] is conducted to represent a qualitative risk assessment which consists of task analysis as function definitions.

The Functional Resonance Accident Model and Functional Resonance Analysis Method [4] are being developed to enable Resilience Engineers to model complex socio-technical systems for the purposes of risk assessment [5] And accident analysis [6] [7]. In this approach Risk assessment goes beyond component failures to look at system dynamics and must consider issues of non-linear risk assessment, furthermore the emergence of faults from usual performance variability can be construed by the concept of functional resonance, derived from the theory of stochastic resonance. The non-linear socio-technical interaction in system was taken into account to consider the impact of human activities on system's safety level.

It should be noted that since all operation are assumed to be performed at same time, it is not possible to consider the variability and resonance of all functions in an entire accident scenario. Hence, the risk assessment is conducted for an operation as a specific resonance in the FRAM network with considering the human errors. This resonance is based on variabilities of the functions in the case study of the paper.

Quantifying the error potential of the actions is provided by an analytical approach: Success Likelihood Index Methodology (SLIM) [8]. Such an approach is also critical in order to ensure accurate quantification of risk. If 
significant human contributors to the likelihood of major accidents occurring are omitted, then the probability of the event occurring may be seriously underestimated. Conversely, the role of the human in enhancing the reliability of a system needs to be taken into account. Though dozens of Quantitative Risk Assessment techniques are employed today, most suffer from lack of calculation of Human Error likelihood. The main focus of the paper is improving Human Error Probabilities (HEP) to have better Quantitative Risk Assessment (QRA). For handling data scarcity, multi-expert judgment is used. Performance Shaping Factors (PSFs) are identified and evaluated. In the last step, an Event Tree (ET) for provided resonance based on FRAM network is presented to evaluate the Quantitative Risk Assessment (QRA).

\section{Risk-Based Approach}

A risk-based methodology is developed to assess the risk of studied operation as illustrated in Figure 1 Methodology applied to estimate HEP and Consequences failures, including Task Analysis, Qualitative Risk Assessment and Quantitative Risk Assessment. Each of these levels consists of several steps. Qualitative Risk Assessment and Quantitative Risk Assessment are presented by applying Functional Resonance Analysis Method (FRAM), Success Likelihood Index Methodology (SLIM) and Event Tree (ET) respectively. The HEPs are estimated by applying the SLIM process. The probability of other hazard-promoting events is calculated by using Homogeneous Poisson Process (HPP). After obtaining the HEPs based on a specific scenario, the final value of the risk is calculated by integrating the HEPs and consequence analysis results (Risk Assessment).

\section{Task Analysis}

Task Analysis (TA) is a fundamental methodology in the assessment and reduction of human error and their relative risk. TA methods can be used to eliminate the preconditions that give rise to errors before they occur. They can be used as an aid in the design stage of a new system, or the modification of an existing system. Task

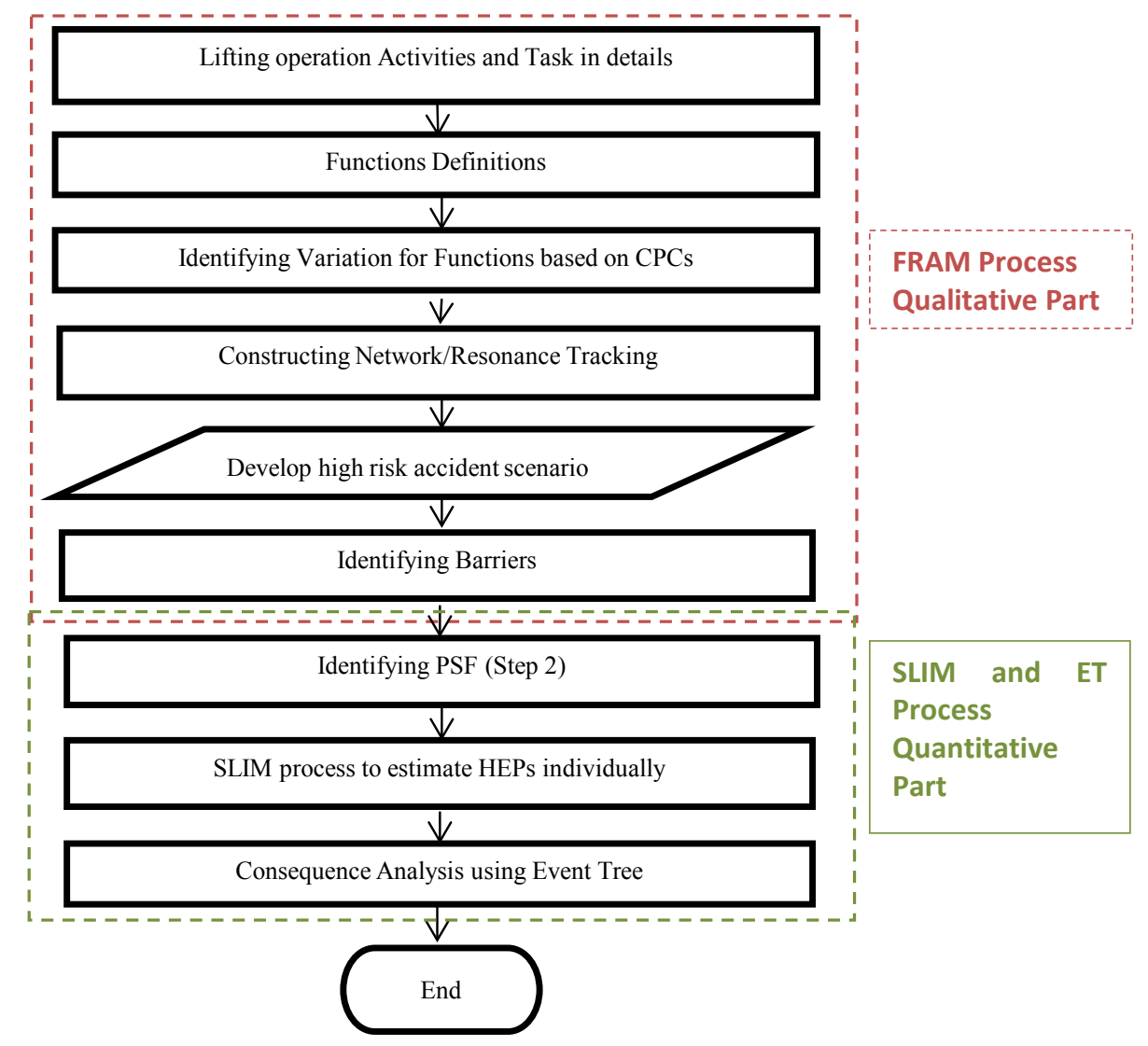

Figure 1. Methodology applied to estimate HEP and Consequences failures. 
analysis can also be used in a retrospective mode during the detailed investigation of major incidents. The starting point of such an investigation must be the systematic description of the way in which the task was actually carried out when the incident occurred [9].

When the scenario is developed, the human related activities and the probability of error for each activity is identified. A summarized representation for different activities and tasks for lifting operation procedure are presented in Table 1 . The major activity involves the mobilization tasks which require safely located and securely fitted and easily accessible and operated. However, all of possible interaction for lifting sub-activities in its equivalent FRAM network (see Figure 2).

\section{Human error Improper connection Lack of control Slamming Disconnection}

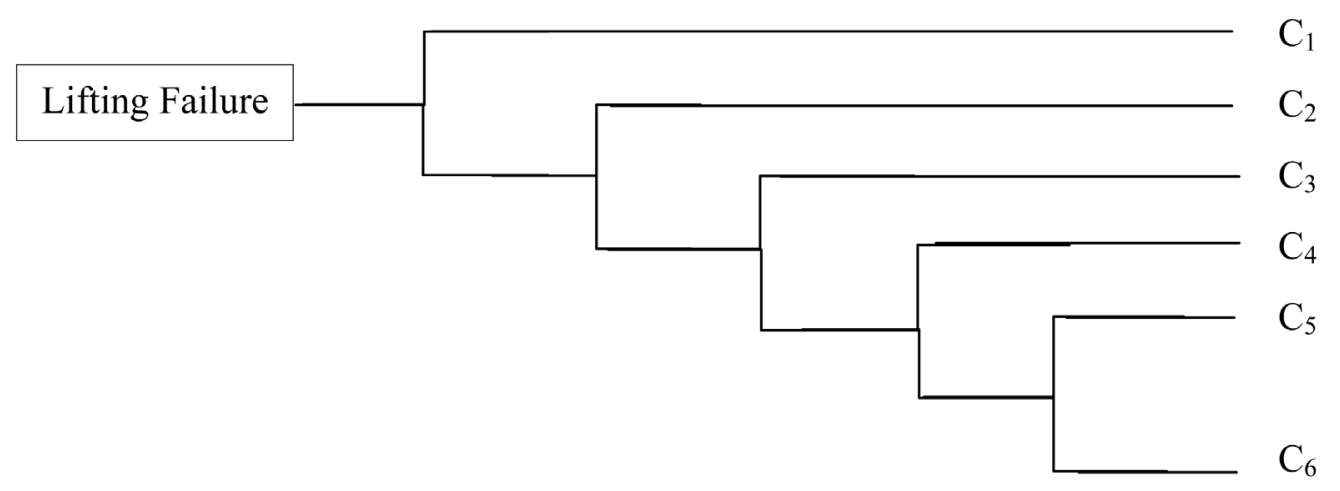

Figure 2. Event tree developed for light lifting in the sea.

Table 1. Human related Activities during lifting operation.

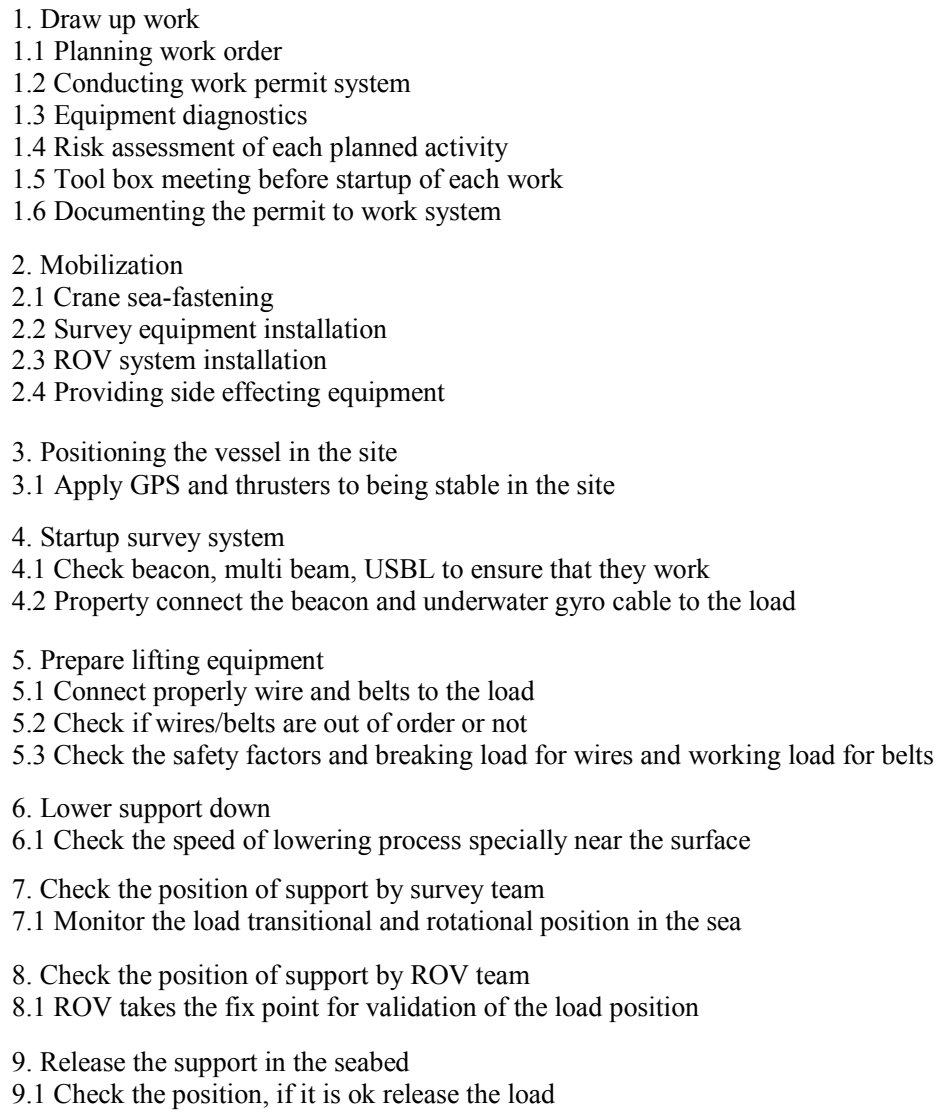




\section{Functional Resonance Analysis Method (FRAM)}

The Functional Resonance Accident Model and its associated Functional Resonance Analysis Method (FRAM; [4]) are systemic models and methods that consider safety as an emergent property of the socio-technical system as a whole. In this approach functions and function performance are the units of analysis Rather than physical components and sequences of events. It is a risk model reviewing non-linear interactions and it is reviewing everyday activity when things are working as they should do. By describing operations when they are functioning you can find out how and why something goes wrong in the system. A function may be defined as "a set of actions that a system performs or is used for, which are valuable for the achievement of a set of goals" [10].

FRAM is based on four principles [7] Compatible with the postulates that form the basis of Resilience Engineering [11]. First, both successes and failures result from the adaptations that organizations, groups and individuals perform in order to cope with complexity. Success is measured in the ability of an organization, group or individual to anticipate the risk and critical situations, to recognize them in time and to make appropriate action. Failure is a result of temporary or permanent absence of this ability. Second, due to the fact that nothing could be as complete as predicted and planned, adjustments must always be made. The third principle states that how variability from multiple functions may combine in unexpected ways, leading to disproportionately large consequences. Fourth the variability of a number of functions may at some occasion reinforce each other and thereby cause the variability of one function to exceed its normal limits. The consequence may spread through tight couplings rather than via identifiable and enumerable cause-effect links.

The FRAM network of studied operation is presented (Figure 2). This network is a basis of quantitative risk assessment of this paper. In the FRAM network of present case study functions with green color are background function which provide a support for foreground function. The functions with blue color are foreground function. Foreground function directly can lead to a failure in lifting process.

As it is obvious from FRAM network the process has 14 functions, 7 background and 7 foreground. The functions are coupled with each other via their common aspects. There are some functions with barrier goal such as quality control, winch control and Connecting Wire/Belts and inspection of connection. Lack of functional barriers make some functions of the operation such as Under Water Gyro/Beacon, USBL system, Lifting support by Crane, vulnerable against unpredictable variabilities.

It should be noted that since all operation are assumed to be performed at same time, it is not possible to consider the variability and resonance of all functions in an entire accident scenario. Hence, the risk assessment is conducted for an operation as a specific resonance in the FRAM network with considering the human errors. This resonance is based on variabilities of the functions (it is specified by numbers). The resonance is a detectable signal that emerges from the unintended interaction of the variabilities of many functions that together may combine in unexpected ways, leading to consequence that are disproportionally large [12].

\section{Human Error Probability Estimation by SLIM Process}

After developing a high-risk accident scenario qualitatively based on FRAM, it is needed to find the probability of error for each human related lifting activity which is one of the main parts of consequences in event tree for risk assessment. Without estimating human error probability (HEP) the final failure estimation for top event in event tree will not be plausible. Since the majority of errors during the operation are due to human errors. Different activities and tasks are identified for this purpose in Table 1.

The SLIM integrates various Performance Shaping Factors (PSFs) relevant to a task into a single number called a success likelihood index (SLI). The SLI is calculated by the following formula (see Equation (1)). For numerous sub-activities for each task then SLI should be calculated for each sub-activity separately and consequently the related HEP should be calculated by Equation (2) in which, " $n$ " is the number of sub-activity and " $m$ " is the number of PSFs to find related SLI for task $j^{\text {th }}$, besides, R and W are the Rate and Weight of each PSF respectively.

$$
\begin{gathered}
S L I=\sum_{i=1}^{m} R_{i} W_{i} \\
S L I_{j}=\sum_{j=1}^{n} \sum_{i=1}^{m} R_{i j} W_{i} .
\end{gathered}
$$


For a given SLI, the human-error probability (HEP) for a task is estimated by using the Equation (3):

$$
\begin{gathered}
\log (H E P)=a \times S L I+b \\
H E P=10^{a \times S L I+b}
\end{gathered}
$$

where $a$ and $b$ are constants determined from two or more tasks for which HEPs are known. In this study $a$ and $b$ are considered as -1.95 and $10 \mathrm{E}-04$, respectively.

Identifying PSFs is a substantial step of presenting the SLIM. The first step of Human Reliability Assessment is to focus on human behavior and identify a set of human factors believed to be related to performance. These PSFs are then employed to estimate the probability of human error in a given situation [13].

\subsection{Identification PSFs}

Performance shaping factor is provided basis for considering potential influences on human performance and systematically considering them in quantification of Human Error Probabilities (HEPs). PSFs often characterized as internal and external. Internal PSFs are influences that the individual brings to the situation such as mood, fitness, stress level, etc. External PSFs are influences in the situation or environment that affect the individual such as temperature, noise, work practices, etc. Currently there is no standard set of PSFs used in HRA methods, but most sets use PSFs identified in human performance literature [14]. Personal factors include, attention [8] attitude [15], personality [8], fatigue [8], knowledge [8], [16], experience [16], [18], motivation [17]. Additional factors include communication [16] [18], teams [19] [20], leadership [21], safety culture [22], ergonomics [23], training [8], [16], environment [17], management [19], time [24] and workload [19]. PSFs are used to meet multiple goals in HRA and the study of human performance. PSFs are used to pin-point positive or negative influences on human performance and to predict conditions that lead to human errors. Several HRA methods use the state (level of influence) of the PSFs to estimate HEPs or to gain qualitative insight about the scenario. PSF states are defined on different scales depending on the selected method, but they generally range from low to high influence.

\subsection{PSFs Assessment}

Determining the weight of PSFs to estimate the SLIs is one of the most pivotal steps. Human performance data with greater detail is difficult to find in real world situations, which requires the use of expert judgment techniques [13]. In this assessment, the PSFs with highest ranks are taken into account as the related PSFs, listed in Table 2. The number in the second column denotes the normalized importance (weight Wi) of a particular PSF for the task under consideration, as determined by experts.

Rating the PSFs is another important step in the SLIM procedure. Participant experts such as technical engineers select rating R from 0 to 1 for each of PSFs. Each PSF rating has an ideal value of 1 at which human performance is judged to be optimal. These ratings are based on six PSFs demonstrated in Table 2 as the most important ones in lifting of light structures. It is necessary to mentioned that, Human error assessment is faced up with uncertainty, especially in any modern and novel industry like offshore industry. In these technologies, the problem of Minimum field data in regard to major component is inevitable. The main reason of uncertainty in

Table 2. Rank and weight of PSFs.

\begin{tabular}{ccc}
\hline PSF & Rank & Weight \\
Experience & 10 & 0.21 \\
Skill & 9 & 0.19 \\
Motivation & 8 & 0.17 \\
Stress level & 7 & 0.15 \\
Work Memory & 7 & 0.15 \\
Time pressure & 6 & 0.13 \\
\hline
\end{tabular}


such technologies is the lack of knowledge with regard to inappropriate or missing experimental and operational data. As a result, a combination of qualitative and quantitative risk assessment with expert judgment could result in a better interpretation of system based on epistemic knowledge and subsequently a better ability to cope with scarce in operational experience and uncertainty.

By applying Equation (2) SLI were obtained for each activity. Afterward, Equation (3) and Equation (4) are used to calculate the HEP of each task. Human Error Probability of activities is presented in Table 3.

It is obvious that the first top event for related ET is related to human error. So, it is necessary to compute the cumulative probability of the first top event, Human error, using the probabilities of the sub-activities based on Equation (4). Assuming that these activities and sub-activities are independent to find the worst-case scenario (The reason is that the independency indicates that the output of following event occurs if any of the input subevents occur), then, the probability of human error, $\mathrm{HEP}_{\mathrm{T}}$, for light structure's lifting in the offshore industry can be calculated using Equation (5).

$$
H E P_{T}=1-\prod_{j=1}^{n}\left(1-H E P_{j}\right) .
$$

Table 3. Human error probability.

\begin{tabular}{|c|c|c|c|c|}
\hline & \multirow{2}{*}{ Activity } & \multirow{2}{*}{ HEP } & \multicolumn{2}{|c|}{ Uncertainty } \\
\hline & & & Lower bound & Upper bound \\
\hline & $\begin{array}{l}\text { Draw up work } \\
\text { Planning work order }\end{array}$ & $9.73 \mathrm{E}-02$ & $6.21 \mathrm{E}-02$ & $1.53 \mathrm{E}-01$ \\
\hline 1.2 & Conducting work permit system & $6.56 \mathrm{E}-02$ & $3.81 \mathrm{E}-02$ & $1.23 \mathrm{E}-01$ \\
\hline 1.3 & Equipment diagnostics & $7.24 \mathrm{E}-02$ & $4.62 \mathrm{E}-02$ & $1.23 \mathrm{E}-01$ \\
\hline 1.4 & Risk assessment of each planned activity & $7.21 \mathrm{E}-02$ & $5.51 \mathrm{E}-02$ & $1.13 \mathrm{E}-01$ \\
\hline 1.5 & Tool box meeting before startup of each work & $9.88 \mathrm{E}-02$ & $6.3 \mathrm{E}-02$ & $1.32 \mathrm{E}-01$ \\
\hline 1.6 & Documenting the permit to work system & $8.4 \mathrm{E}-02$ & $5.36 \mathrm{E}-02$ & $1.44 \mathrm{E}-01$ \\
\hline & $\begin{array}{l}\text { Mobilization } \\
\text { Crane sea-fastening }\end{array}$ & $9.03 \mathrm{E}-02$ & $5.34 \mathrm{E}-02$ & $1.55 \mathrm{E}-01$ \\
\hline 2.2 & Survey Equipment Installation & $9.48 \mathrm{E}-02$ & $6.05 \mathrm{E}-02$ & $1.48 \mathrm{E}-01$ \\
\hline 2.3 & ROV system Installation & $8.87 \mathrm{E}-02$ & $5.15 \mathrm{E}-02$ & $1.52 \mathrm{E}-01$ \\
\hline 2.4 & Providing side effecting equipment & $1.08 \mathrm{E}-01$ & $6.12 \mathrm{E}-02$ & $1.79 \mathrm{E}-01$ \\
\hline $\begin{array}{l}3 . \\
3.1\end{array}$ & $\begin{array}{l}\text { Positioning the vessel in the site } \\
\text { Apply GPS and thrusters to being stable in the site }\end{array}$ & $1.05 \mathrm{E}-01$ & $5.71 \mathrm{E}-02$ & $2.11 \mathrm{E}-01$ \\
\hline & $\begin{array}{l}\text { Start-up survey system } \\
\text { Check beacon, multi beam, USBL to ensure that they work property }\end{array}$ & $9.71 \mathrm{E}-02$ & $5.23 \mathrm{E}-02$ & $1.92 \mathrm{E}-01$ \\
\hline 4.2 & Connect the beacon and underwater gyro cable to the load & $9.92 \mathrm{E}-02$ & $6.77 \mathrm{E}-02$ & $2.11 \mathrm{E}-01$ \\
\hline & $\begin{array}{l}\text { Prepare Lifting Equipment } \\
\text { Connect properly wire and belts to the load }\end{array}$ & $8.18 \mathrm{E}-02$ & $4.75 \mathrm{E}-02$ & $1.46 \mathrm{E}-01$ \\
\hline 5.2 & Check if wires/belts are out of order or not & $1.01 \mathrm{E}-01$ & $6.08 \mathrm{E}-02$ & $1.58 \mathrm{E}-01$ \\
\hline 5.3 & Check the safety factors and breaking load for wires and working load for belts & $8.00 \mathrm{E}-02$ & $5.24 \mathrm{E}-02$ & $1.82 \mathrm{E}-01$ \\
\hline & $\begin{array}{l}\text { Lower support down } \\
\text { Check the speed of lowering process specially near the surface }\end{array}$ & $1.27 \mathrm{E}-01$ & $6.11 \mathrm{E}-02$ & $2.11 \mathrm{E}-01$ \\
\hline & $\begin{array}{l}\text { Check position of support by Survey Team } \\
\text { Monitor the load transitional and rotational position in the sea }\end{array}$ & $1.09 \mathrm{E}-01$ & $5.15 \mathrm{E}-02$ & $1.78 \mathrm{E}-01$ \\
\hline & $\begin{array}{l}\text { Check position of support by ROV team } \\
\text { ROV takes the fix point for validation of the load position }\end{array}$ & $1.09 \mathrm{E}-01$ & $5.15 \mathrm{E}-02$ & $1.78 \mathrm{E}-01$ \\
\hline $\begin{array}{l}9 . \\
9.1\end{array}$ & $\begin{array}{l}\text { Release the support on seabed } \\
\text { Check the position, if it is ok release the load }\end{array}$ & $1.36 \mathrm{E}-01$ & $6.99 \mathrm{E}-02$ & $2.18 \mathrm{E}-01$ \\
\hline
\end{tabular}




\section{Quantitative Risk Assessment by Using Event Tree}

Applying a continuous improvement in the system Safety Management in any kinds of process in the industries needs different approach such as Risk Assessment. The expected achievements of risk Management is that the hazards and risks of the system were identified, analyzed, assessed, evaluated, controlled and finally reduced. In the assessment phase, different approaches are used such as Quantitative Risk Assessment (QRA) and probabilistic safety assessment (PSA). Among several techniques available as a Quantitative Risk Assessment (QRA), Event Tree (ETs) have widely been used to explore the probability of consequences resulted from an initiating event. It has been used successfully in the nuclear industry, the chemical process industry, and in several other application areas. Event tree analysis is also commonly used for human reliability assessment. The method is inductive and follows a forward logic [1].

\subsection{Homogeneous Poisson Process (HPP)}

In probability theory and statistics, the Poisson distribution is a discrete probability distribution that expresses the probability of a given number of events. The occurrences of the hazardous event are often modeled by a homogeneous Poisson process with frequency of failure rate $\lambda$, which is the expected number of occurrences per year (or some other time unit).

We use Poisson distribution to find probabilities of occurrences of hazard-promoting factors sequences. The failure rate estimates are based on Recorded failure events, Expert judgment and Laboratory testing and in some cases a combination of these. The HPP of hazardous events of the event tree in Figure 3 are calculated by using Equation (6) [25] and indicated in Table 4. However, the probability of the first top event, Human error, has been derived using Equation (5)

$$
\operatorname{Pr}(N(t)=n)=\frac{(\lambda t)^{n}}{n !} \mathrm{e}^{-\lambda t} \text { for } n=0,1,2, \cdots
$$

\subsection{Event Tree Approach Developed for Light Lifting}

It should be noted that since all operation are assumed to be performed at same time, it is not possible to consider the variability and resonance of all functions in an entire accident scenario. Hence, the risk assessment is conducted for an operation as a specific resonance in the FRAM network with considering the human errors. Based on accident reports, related research and expert opinions, the most probable accident scenario is the provided resonance in the FRAM network in which a human error may lead to inappropriate checking of the connection between belt and trunnion. Besides inadequate control in the speed of the load in lowering process, specially near the surface may increase the probability of failure that is slamming of the load and consequently disconnection of load and derrick. The resulting diagram displays the mentioned accident scenarios (see Figure 2). The occurrences of the hazard-promoting event are often modeled by a homogeneous Poisson process with frequency $\lambda[1]$.

Applying the probabilities of hazard-promoting factors, the probabilities of consequences can be calculated for light lifting in the sea (Table 5).

\section{Frequency Histogram for Light Lifting Accident}

By working through the entire event tree, we produce a spectrum of light lifting failure and their probability for the various accident sequences (Figure 3). As it is obvious from histogram, the probability of hazard-promoting

Table 4. Probability of each hazard-promoting factors of event tree.

\begin{tabular}{cc} 
Hazard-promoting factors & Probability \\
Human error (HEPT) & 0.86 \\
Improper connection between belt and trunnion & 0.08 \\
Lack of speed control in lowering process & 0.11 \\
Slamming & 0.10 \\
Disconnection & 0.12 \\
\hline
\end{tabular}




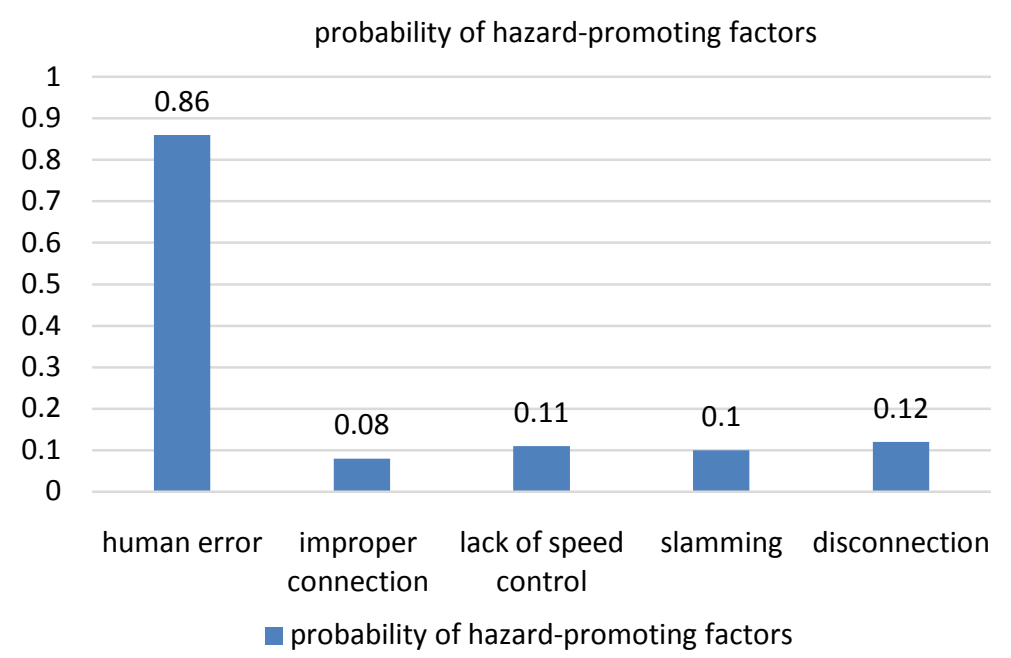

Figure 3. Frequency histogram for lifting failure.

Table 5. Risk assessment of lifting failure accidents.

\begin{tabular}{ccc}
\hline Index & End state description & Probability \\
\hline $\mathrm{C}_{1}$ & Safe condition & $1.4 \mathrm{E}-01$ \\
$\mathrm{C}_{2}$ & Mishap & $7.91 \mathrm{E}-01$ \\
$\mathrm{C}_{3}$ & Near miss & $6.1 \mathrm{E}-02$ \\
$\mathrm{C}_{4}$ & Improper fastening of connection points like shackles, \\
$\mathrm{C}_{5}$ & belts or slings; successful installation; without damage & $6.81 \mathrm{E}-03$ \\
$\mathrm{C}_{6}$ & Slamming; successful installation; minor property damage & $6.65 \mathrm{E}-04$ \\
\hline
\end{tabular}

factors reached a pick in human error. It depicts two matters, firstly the importance of human error rule and secondly is that without considering human error in the processing of light lifting risk assessment there is a striking difference in the final outcomes.

\section{Conclusion}

A risk-based approach has been conducted to assess the risks of light lifting in offshore industry. This methodology consists of Task Analysis, Qualitative Risk Assessment and Quantitative Risk Assessment. The aim is to illustrate the importance of the role of human error in evaluating and estimating the risks of system with pinpoint accuracy. To do so, risk assessment in this study is divided into two parts: Qualitative Risk Assessment and Quantitative Risk Assessment. The HEPs are estimated by applying the SLIM process. The probability of other hazard-promoting events is calculated by using Homogeneous Poisson Process (HPP). Although quantitative risk assessment and probabilistic safety analyzing are vital and necessary for system safety management, the study showed that by eliminating the role of human reliability in the assessment, the effectiveness and accuracy of evaluation will decline enormously. After obtaining the HEPs based on a specific scenario, the final value of the risk is calculated by integrating the HEPs and consequence analysis results (Risk Assessment). The main challenges experienced for this study are data scarcity and uncertainty in expert opinion. By applying multi-expert knowledge, this paper presents a methodology to overcome these two major limitations.

\section{References}

[1] Rausand, M. (2011) Risk Assessment. John Wiley \& Sons, New Jersey. http://dx.doi.org/10.1002/9781118281116

[2] Swain, A.G. (1983) Handbook of Human Reliability Analysis with Emphasis on Nuclear Power. US Nuclear Regula- 
tory, Washington.

[3] Blackman, H.G. (2008) Human Error Quantification Using Performance Shaping Factors in the SPAR-H Method. 52nd Annual Meeting of the Human Factors and Ergonomics Society, New York, 22-26 September 2008, 1733-1738. http://dx.doi.org/10.1177/154193120805202109

[4] Hollnagel, E. (2004) Barriers and Accident Prevention. Ashgate, Aldershot.

[5] Lundblad, K.S. (2008) FRAM as a Risk Assessment Method for Nuclear Fuel Transportation. Proceedings of the 4th International Conference Working on Safety, Crete, 30 September-4 October 2008.

[6] Woltjer, R. (2007) The Alaska Airlines Flight 261 Accident: A Systemic Analysis of Functional Resonance. Proceedings of the 2007 (14th) International Symposium on Aviation Psychology, Dayton, Ohio, 24 April 2007, 763-768.

[7] Hollnagel, E.P. (2008) A Functional Resonance Accident Analysis of Comair Flight 5191. 8th International Symposium of the Australian Aviation Psychology Association, Sydney, 8-11 April 2008.

[8] Kirwan, B. (1994) A Guide to Practical Human Reliability Assessment. Taylor \& Francis, London.

[9] Embrey, D. (2000) Task Analysis Techniques. Human Reliability Associates Ltd.

[10] Woltjer, R. (2009) Functional Modeling of Constraint Management in Aviation Safety and Command and Control. Linkoping Studies in Science and Technology, Linkoping University, Sweden, Dissertation No. 1249.

[11] Hollnagel, E.W. (2006) Resilience Engineering: Concepts and Precepts. Ashgate, Aldershot.

[12] Herrera, I. (2010) Comparing a Multi-Linear (STEP) and Systemic (FRAM) Method. Reliability Engineering and System Safety, 95, 1269-1275. http://dx.doi.org/10.1016/j.ress.2010.06.003

[13] Mashrura Musharraf, J.H. (2013) Human Reliability Assessment during Offshore Emergency Conditions. Safety Science, 59, 19-27. http://dx.doi.org/10.1016/j.ssci.2013.04.001

[14] Groth, K. (2009) A Data-Informed Model of Performance Shaping Factors for Use in Human Reliability Analysis. Doctoral Dissertation, University of Maryland, College Park, MD.

[15] Triandis, H. (1991) Attitude and Attitude Change. In: Encyclopedia of Human Biology, Academic Press, San Diego, CA, 485-496.

[16] Gertman, D.I., Hallbert, D.I. (2001) Review of Findings for Human Error Contribution to Risk in Operating Events. Idaho National Engineering and Environmental Laboratory, Idaho, Idaho Falls.

[17] Barnes, V.E. and Haagensen, B.C. (2001) The Human Performance Evaluation Process: A Resource for Reviewing the Identification and Resolution of Human Performance Problems. US Nuclear Regulatory Commission, Washington DC, Tech. Rep. NUREG/CR-6751.

[18] Gemuenden, M.H. (2001) Teamwork Quality and the Success of Innovative Projects: A Theoretical Concept and Empirical Evidence. Organization Science, 12, 435-449. http://dx.doi.org/10.1287/orsc.12.4.435.10635

[19] Reason, J. (1997) Managing the Risks of Organizational Accidents. Ashgate, London.

[20] Copper, B.M. (1994) The Relation between Group Cohesiveness and Performance: An Integration. Psychological Bulletin, 115, 210-227. http://dx.doi.org/10.1037/0033-2909.115.2.210

[21] Sasou, K., Takano, K. and Yoshimura, S. (1996) Modeling of a Team's Decisionmaking Process. Safety Science, 24, 13-33. http://dx.doi.org/10.1016/S0925-7535(96)00029-X

[22] Burack, R.C. (1987) Measuring Norms and Expectations with the OCI. Human Synergistics, Organizational Culture Inventory Level V Manual, Chicago, Illinois.

[23] Kecklund, L.J. and Svenson, O. (1997) Human Errors and Work Performance in a Nuclear Power Plant Control Room: Associations with Work-Related Factors and Behavioral Coping. Reliability Engineering and System Safety, 56, 5-15. http://dx.doi.org/10.1016/S0951-8320(96)00137-8

[24] Edwards, J.F. (1998) Time Pressure, Task Performance, and Enjoyment. In: McGrath, J., Ed., The Social Psychology of Time, Sage Publications, Newbury Park.

[25] Ross, S. (2010) A First Course in Probability. 8th Edition. Pearson, NJ. 